\title{
Human malaria diagnosis using a single-step direct-PCR based on the Plasmodium cytochrome oxidase III gene
}

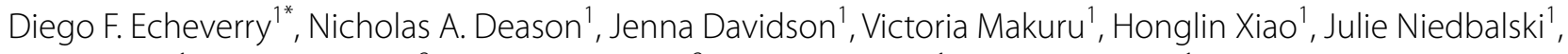
Marcia Kern', Tanya L. Russell ${ }^{2}$, Thomas R. Burkot ${ }^{2}$, Frank H. Collins ${ }^{1}$ and Neil F. Lobo ${ }^{1}$

\begin{abstract}
Background: Nested PCRs based on the Plasmodium 18s-rRNA gene have been extensively used for human malaria diagnosis. However, they are not practical when large quantities of samples need to be processed, further there have been challenges in the performance and when interpreting results, especially when submicroscopic infections are analysed. Here the use of "direct PCR" was investigated with the aim of improving diagnosis in the malaria elimination era.

Methods: The performance of the Plasmodium cytochrome oxidase III gene (COX-III) based novel malaria detection strategies (direct nested PCR and direct single PCR) were compared using a 18s-rRNA direct nested PCR as a reference tool. Evaluations were based on sensitivity, specificity and the ability to detect mixed infections using control blood spot samples and field collected blood samples with final species diagnosis confirmation by sequencing.

Results: The COX-III direct PCR (limit of detection: 0.6-2 parasites/ $\mu \mathrm{L}$ ) was more sensitive than the 18s-rRNA direct nested PCR (limit of detection: 2-10 parasites/ML). The COX-III direct PCR identified all 21 positive controls (no mixed infections detected) while the 18s-rRNA direct nested PCR identified 18/21 (including four mixed infections). Different concentrations of simulated mixed infections (Plasmodium vivax and Plasmodium falciparum) suggest that the COX-III direct PCR detects only the predominant species. When the 18s-rRNA direct nested PCR was used to detect Plasmodium in field collected bloods spots $(n=3833)$, there was discrepancy in the results from the genus PCR ( $16 \%$ positive) and the species-specific PCR (5\% positive). Further, a large portion of a subset of these positive samples (93\% for genus and $60 \%$ for P. vivax), did not align with Plasmodium sequences. In contrast, the COX-III direct PCR clearly identified (single bands confirmed with sequencing) $2 \%$ positive Plasmodium samples including P. vivax, P. falciparum, Plasmodium malariae and Plasmodium ovale wallikeri.
\end{abstract}

Conclusions: The COX-III single direct PCR is an alternative method for accurate detection of Plasmodium microscopic and submicroscopic infections in humans, especially when a large number of samples require screening. This PCR does not require DNA isolation, is sensitive, quick, produces confident/clear results, identifies all the Plasmodium species infecting humans, and is cost-effective.

Keywords: Malaria, Blood spots, 18s-rRNA, Cytochrome oxidase III, Diagnostic, PCR, Direct PCR, Plasmodium, Plasmodium ovale, Submicroscopic infections

\footnotetext{
*Correspondence: decheve1@nd.edu

' Eck Institute for Global Health, University of Notre Dame, Notre Dame,

IN 46556, USA

Full list of author information is available at the end of the article
} 


\section{Background}

Significant progress has been made in the global fight against malaria through the scaling-up of indoor residual spraying (IRS), insecticide-treated bed nets (ITNs), rapid diagnostic tests (RDTs) and artemisinin-based combination therapy (ACT) [1, 2]. As malaria endemic regions approach pre-elimination, a switch from passive detection to active screening of large numbers of samples will be needed to find and treat asymptomatic infections [3]. Design and implementation of sensitive diagnostic tools are thus needed to detect asymptomatic infections that would otherwise go unnoticed and contribute to the persistence of malaria transmission [4].

Estimates of human malaria prevalence and incidence are dependent on the sensitivity of the diagnostic method. Under field conditions, experienced microscopists typically detect parasitaemias of 50-100 parasites/ $\mu \mathrm{L}$ [5], but misdiagnosis is common with mixed infections and low parasitaemias are often missed. In areas where microscopy is not feasible, rapid malaria diagnostic tests (RDTs) target the lactate dehydrogenase and aldolase proteins found in all Plasmodium species (Pan-specific malaria RDT). The histidine-rich protein 2 (HRP2) based RDT is specific for Plasmodium falciparum [6]. These RDTs have a limit of detection around 200 parasites/ $\mu \mathrm{L}$ and are influenced by other factors such as deletion of target genes, the method of storage and handling of RDTs, concentration of proteins in blood, the manufacturer and subjectivity in interpretation of results which may affect the accuracy of the tests [7-11].

Molecular tools have also been utilized for malaria diagnosis and have improved the capacity to diagnose submicroscopic infections $[12,13]$. These are defined as a low-density of Plasmodium parasites in blood that are unlikely to be detected by conventional microscopy. A meta-analyses of 38 studies comparing the sensitivity of microscopy and PCR for malaria diagnosis demonstrated that an average of 69 and $56 \%$ of Plasmodium vivax and $P$. falciparum infections, respectively, identified as positives through PCR were not detected by microscopy [12].

Since the early 1990s, PCR-based diagnostic methods targeting the small subunit rRNA gene (18s-rRNA) have been routinely used for the detection of human Plasmodium species [14-16]. A nested PCR using this gene is considered the standard for molecular-based malaria diagnosis [3]. The reported diagnostic sensitivity of tests based on the 18s-rRNA target ranges from 1 to 10 parasites/ $\mu \mathrm{L}$ [16-18]. This nested PCR, as well as the mitochondrial cytochrome $b[19,20]$, antigenic genes such as stevor and msa-2 [21], PgMt19 and PfMT869 mitochondrial regions [22], and the Pvr47 and Pfr364 genes $[23,24]$, have allowed screening of field samples for epidemiological studies and characterization of submicroscopic malaria infection. However, the level of sensitivity is variable depending on the method used and characteristics of the target gene.

Recently, a novel technique called "direct PCR", was developed based on DNA amplifications using a genetically modified DNA polymerase with rapid performance in presence of strong inhibitors from blood [25]. As a consequence, DNA extraction and PCR amplification can be combined in a single step, saving resources and time, while minimizing human error and contaminations. Direct PCRs has been used to diagnose infectious diseases $[17,26]$, to detect molecular markers of cancer [27], to identify human pharmacogenomics markers for HIV [28], for forensic genotyping [29] and was applied to malaria diagnosis using the 18s-rRNA following a nested PCR approach $[17,30]$.

Nested PCRs are still routinely used to identify Plasmodium genus and species. This may be impractical for diagnosis in the malaria elimination era, where the proportion of submicroscopic infections are expected to increase $[4,31]$ and larger number of samples will be required for human malaria epidemiology studies. The main goal of this study is to provide faster and more sensitive molecular tools to improve malaria diagnosis in the era of malaria elimination programmes. The use of a direct single PCR based on the Plasmodium cytochrome oxidase gene (COX-III) was investigated and compared against the 18s-rRNA direct nested PCR for malaria diagnosis.

\section{Methods}

\section{Parasite reference strains and positive control blood samples}

Malaria parasites (in blood spots or as extracted DNA) from $P$. falciparum (HB3 strain), P. vivax (AMRU1 and MIAMI strains), Plasmodium ovale (I.D 5463) and Plasmodium knowlesi (Malayan strain) were provided by Michael Ferdig (University of Notre Dame, USA), Robert D. Cooper (Australian Army Malaria Institute, Australia) and the Malaria Research and Reference Reagent Resource Center (MR4) USA, Harald Noedl (Medical University of Vienna, Austria), and John W. Barnwell (Centers for Disease Control and Prevention, USA), respectively. Microscopy was used to determine parasite densities of $P$. vivax (AMRU1) obtained from Aotus monkeys and $P$. falciparum (HB3) from continuous culture (about $70 \%$ rings), which were serially diluted and blotted on filter paper ranging from 500 to one parasites/ $\mu \mathrm{L}$ and $500-0.06$ parasites $/ \mu \mathrm{L}$, respectively. Twenty-one malaria positive (as diagnosed by microscopy) blood samples were included as positive controls. 


\section{Field human blood samples collection}

A total of 3833 finger-prick human blood samples were collected in the Western Province of the Solomon Islands. Blood was spotted onto filter paper (Whatman 3 MM, Whatman International, Maidstone, England) and air dried at ambient temperature before storage in individual plastic bags with silica gel. Ethical approval for the study was obtained from University of Notre Dame, USA (FWA 00002462); National Health Research and Ethics Committee, Solomon Islands (HRC13/14 and HRC14/16); and the James Cook University Human Research Ethics Committee, Australia (H4915). Informed consent was sought from all the subjects who provided blood samples.

\section{Preparation of blood spots}

For each sample, two $1.5 \mathrm{~mm}$ diameter samples of dried blood (equivalent to 3-5 $\mu \mathrm{L}$ of blood) [32] were placed in the well of a 96-well PCR microplate (Axygen Scientific, Union City, CA). Each plate included two positive controls (P. vivax or P. falciparum) and three negative controls (two blood spots from a known malaria negative donor and one no-template reaction control). To remove haemoglobin, $70 \mu \mathrm{L}$ of molecular biology grade water (Cellgro-Mediatech INC, Manassas, VA) were added to each well and the plate was incubated at $50^{\circ} \mathrm{C}$ for five min, $21{ }^{\circ} \mathrm{C}$ for $15 \mathrm{~s}, 50{ }^{\circ} \mathrm{C}$ for $1.5 \mathrm{~min}$, and $21^{\circ} \mathrm{C}$ for $15 \mathrm{~s}$. The water was then removed from each well and discarded.

\section{Malaria genus PCR based on the 18s-rRNA (direct nested PCR)}

A direct nested PCR strategy targeting the 18s-rRNA gene using the Blood Phusion Direct PCR Kit (Thermo Scientific, Waltham, MA) as described by Fuehrer et al. [17] was followed with modifications (Table 1). For the nest1 protocol, a total master-mix volume of $25 \mu \mathrm{L}$ was added directly to the wells containing blood spots (Fig. 1, Table 1). After nest1 completion, the microplate was centrifuged at room temperature at $1000 \mathrm{G}$ for $3 \mathrm{~min} .3 \mu \mathrm{L}$ of nest1 PCR product were transferred to a new microplate in order to perform the nest 2 reaction (Fig. 1, Table 1) with a final volume of $20 \mu \mathrm{L}$. Nest2 PCR products were analysed by gel electrophoresis in a $1.5 \%$ agarose gel stained with ethidium bromide (Sigma-Aldrich, St. Louis, $\mathrm{MO})$.

\section{8s-rRNA PCR for Plasmodium vivax and Plasmodium falciparum diagnosis}

Malaria-species diagnosis [17] (nest2 PCR) was performed on positive samples from the malaria-genus PCR (presence of a $235 \mathrm{bp}$ band), on the reference strains serial dilutions and on 21 positive control samples. As $P$. vivax (band of $121 \mathrm{bp}$ ) and P. falciparum (band of
$200 \mathrm{bp})$ are the most prevalent species worldwide, separate rounds of nest2 PCRs were performed for diagnosis of both species using $3 \mu \mathrm{L}$ of nest1 PCR product and a master-mix volume of $15 \mu \mathrm{L}$ (Fig. 1, Table 1). Nest2 PCR products were analysed as above using a $2.0 \%$ agarose gel. All 18s-rRNA PCR assays were amplified on an Eppendorf Master Cycler (Eppendorf) or GeneAmp PCR System 9700 (Applied Biosystems) machines.

\section{Cytochrome oxidase III primer design}

The mitochondrial genome sequences ( 5900 nucleotides) from $P$. vivax [GenBank: KF668441.1], P. falciparum [GenBank M99416.1], Plasmodium malariae [GenBank AB489194.1], Plasmodium ovale wallikeri [GenBank HQ712053.1], Plasmodium ovale curtisi [GenBank HQ712052.1], and P. knowlesi [GenBank AY722797.1] were aligned using MultAlin software [33]. A visual inspection of the alignment demonstrated several blocks of polymorphic sequences delimitated by conserved sequences among the Plasmodium species around the cytochrome oxidase III (COX-III) gene (Fig. 1). A set of primers, plas_cox3F/R (for nest1) and short_COX-III F/R (for nest2) (Table 1), were designed with the highest stringency in parameters using the DNAstar lasergene ${ }^{\circledR}$ 11 software (DNAstar Inc. Madison WI). The annealing temperatures for these primers were determined using the manufacturer's instructions [34].

\section{COX-III Nested and single direct PCR}

Haemoglobin was removed as described. For the nest1 COX-III direct PCR the final reaction volume was $25 \mu \mathrm{L}$ (Table 1). A nest2 PCR was then performed using $2 \mathrm{uL}$ of the nest1 PCR product in a final reaction volume of $25 \mu \mathrm{L}$. For the single direct PCR reactions, the primers short COX-III F/R were used in a $25 \mu \mathrm{L}$ final volume (Fig. 1, Table 1). PCR products were visualized on a $1 \%$ gel stained with SYBR ${ }^{\circledR}$ safe (Invitrogen, Carlsbad, CA).

\section{Mixed infection test using the fast COX-III PCR}

To estimate the performance of the single direct COXIII PCR on simulated mixed infections, the genomic DNA from $P$. falciparum (HB3 strain) and $P$. vivax (Miami strain) cultures were extracted following the protocol described in the E.Z.N.A. Blood DNA Mini Kit (Omega Bio-Tek, Norcross, GA). The concentration of the extracted DNA was determined using the Nanodrop 2000 (Thermo Scientific, Waltham, MA). Eight serial dilutions with a 1:6 factor were prepared for each species DNA. Serial dilutions from one species (from the highest to the lowest) were mixed with the serial dilutions from the other species (from the lowest to the highest) resembling different concentrations of DNAs found in Plasmodium spp. mixed infections (Table 2). 


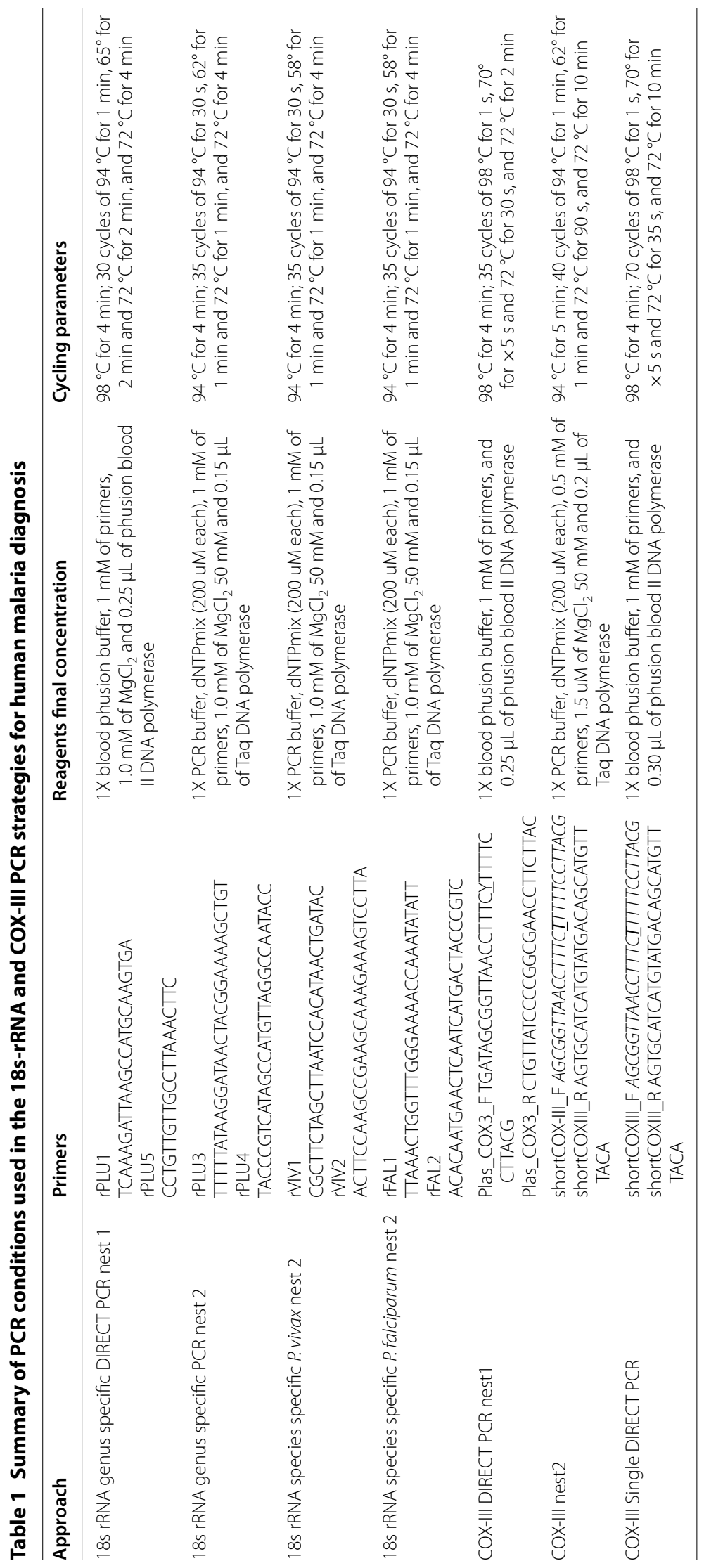




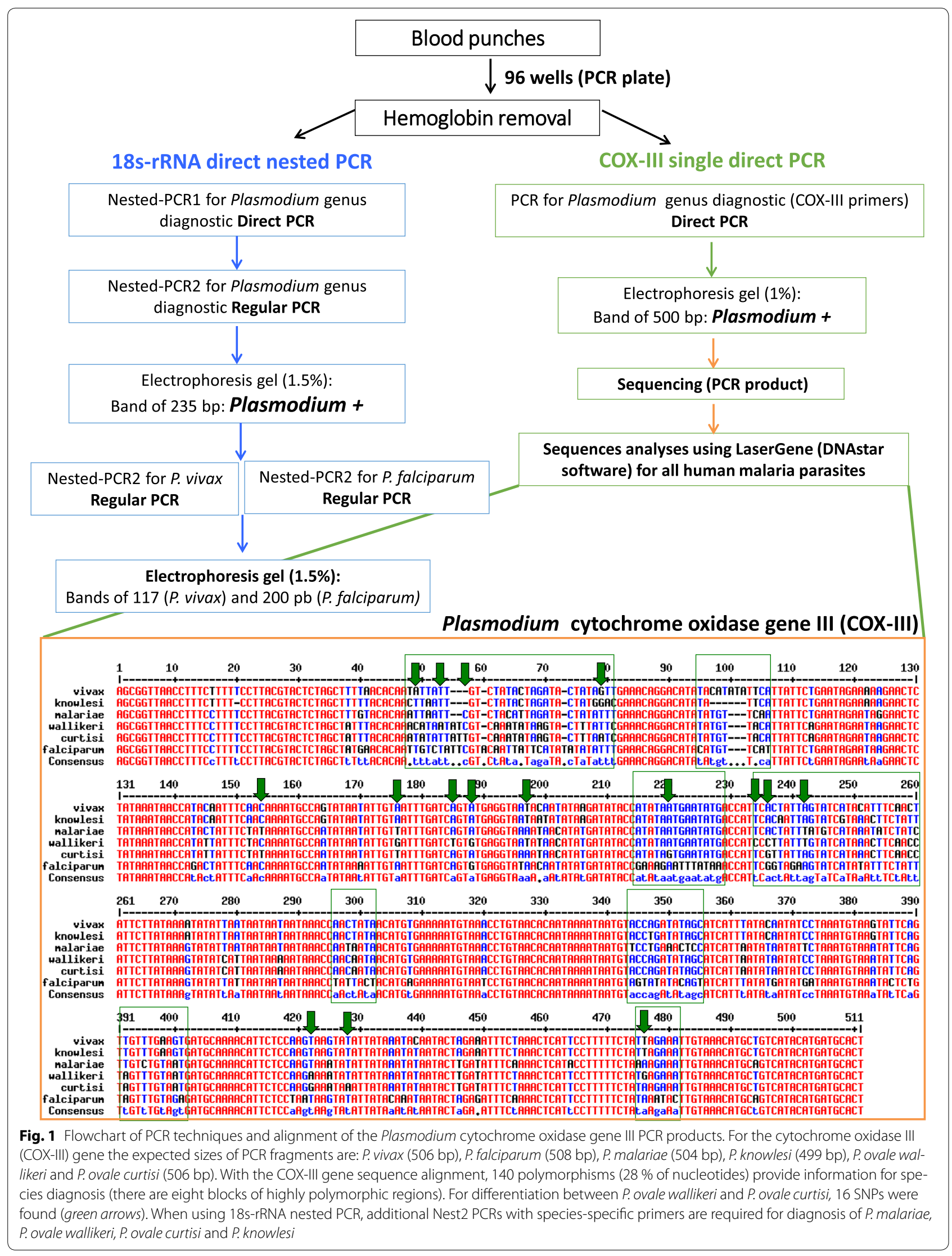


Table 2 Analyses of PCR products (COX-III single directPCR) of Plasmodium spp positive-controls and dilution performance of simulated mixed infections

\begin{tabular}{|c|c|c|}
\hline \multirow[t]{2}{*}{ Plasmodium spp. } & \multicolumn{2}{|l|}{ BLAST result } \\
\hline & $\%$ Identity & Evalue \\
\hline \multicolumn{3}{|c|}{ Plasmodium spp. control (positive) samples } \\
\hline P. falciparum (HB3 strain) & 99.8 & 0.0 \\
\hline P. vivax (AMRU1 strain) & 100 & 0.0 \\
\hline P. malariae (From the field) & 99.8 & 0.0 \\
\hline P. ovale wallikeri (I.D 5463) & 99.3 & 0.0 \\
\hline P. ovale curtisi (From the field) & 98.4 & $3.2 \mathrm{E}-113$ \\
\hline P. knowlesi (Malayan Strain) & 100 & $8.1 \mathrm{E}-180$ \\
\hline \multicolumn{3}{|c|}{$\begin{array}{l}\text { Serial dilutions of mixed samples in ng (higher concentration of } P \text {. vivax } \\
\text { Miami strain) }\end{array}$} \\
\hline $\begin{array}{l}\text { 3.3 } \mathrm{E}-01 \text { P. vivax }+1.1 \mathrm{E}-06 \\
\text { of P. falciparum }\end{array}$ & 98.5 P. vivax & $2.9 E-93$ \\
\hline \multicolumn{3}{|l|}{$\begin{array}{l}5.5 \mathrm{E}-02 \text { P. vivax }+7.14 \mathrm{E}-06 \\
\text { of P. falciparum }\end{array}$} \\
\hline \multicolumn{3}{|l|}{$\begin{array}{l}9.2 \mathrm{E}-03 \text { P. vivax }+4.2 \mathrm{E}-05 \\
\text { of P. falciparum }\end{array}$} \\
\hline \multicolumn{3}{|l|}{$\begin{array}{l}1.5 \mathrm{E}-04 \text { P. vivax }+2.5 \mathrm{E}-04 \\
\text { of P. falciparum }\end{array}$} \\
\hline \multicolumn{3}{|c|}{$\begin{array}{l}\text { Serial dilutions of mixed samples in ng (higher concentration of P. falcipa- } \\
\text { rum HB3 strain) }\end{array}$} \\
\hline $\begin{array}{l}2.5 \mathrm{E}-04 \text { P. vivax }+1.5 \mathrm{E}-04 \\
\text { of P. falciparum }\end{array}$ & 99.5 P. falciparum & $9.4 \mathrm{E}-100$ \\
\hline \multicolumn{3}{|l|}{$\begin{array}{l}\text { 4.2E-05 P. vivax + } 9.2 \mathrm{E}-03 \\
\text { of P. falciparum }\end{array}$} \\
\hline \multicolumn{3}{|l|}{$\begin{array}{l}\text { 7.14E-06 P. vivax }+5.5 \mathrm{E}-02 \\
\text { of P. falciparum }\end{array}$} \\
\hline $\begin{array}{l}\text { 1.1E-06 P. vivax }+3.3 \mathrm{E}-01 \\
\text { of P. falciparum }\end{array}$ & & \\
\hline
\end{tabular}

Serial dilutions 1:6 of eight different mixed concentration of DNA (higher for one species and lower for the other, and vice versa)

\section{Sequencing reactions for species diagnosis}

A set of 100 predictive positive samples for the 18s-rRNA genus malaria diagnosis (with PCR product around 235 bp PCR product), and 20 from the species malaria $P$. vivax PCR (approx. $121 \mathrm{bp)}$ were excised from gels and purified using the QIAquick gel extraction kit (QIAGEN, Valencia, CA) and sequenced with the rPLU3, Plasmo int_2REV (3' CATCAAAAGCTGATAGGTCAGA $5^{\prime}-200$ bp sequence length) and VIV1 primers respectively (Table 1). Eight microliter of PCR product from positive samples from COX-III single direct PCR reactions were purified with the ExoSAP-IT PCR clean-up kit (Affymetrix, Santa Clara, CA) and sequenced with the short_COX-IIIF primer. All sequencing reactions were performed on a MicroAmp Optical 96-well plate (Life Technologies) following the protocol described in the BigDye ${ }^{\circledR}$ Terminator V3.1 kit (Applied Biosystems). The BigDye ${ }^{\circledR}$ was precipitated and samples were resuspended in $10 \mu \mathrm{L}$ of Hi-Di Formamide and sequenced on an ABI 3730XL 96-capillary sequencer. Analyses of sequences were performed using the DNASTAR Lasergene ${ }^{\circledR} 11$ software (DNAstar Inc. Madison WI).

\section{Results}

Lowest parasitaemia detected and validation assay on positive blood samples

The lowest parasitaemia detected by PCR diagnostic assays were estimated using serial dilutions from parasite reference strains ranging from 500 to 0.06 parasites $/ \mu \mathrm{L}$. The lowest parasitaemia consistently detected for P. falciparum and $P$. vivax with the $18 \mathrm{~s}$-rRNA direct nested PCR (in 4/4 replicates) were 2 and 10 parasites/ $\mu \mathrm{L}$, respectively, while for the single direct COX-III PCR was 0.6 parasite $/ \mu \mathrm{L}$ for $P$. falciparum and 2 parasites $/ \mu \mathrm{L}$ for $P$. vivax (in 6/6 replicates) (Fig. 2a, b). Interestingly, the COX-III single direct PCR performed similar to or better than the nested COX-III PCR (data not shown). Since the COX-III single direct PCR was found to be simpler, shorter and more sensitive, the nested COXIII PCR was not analysed further. The addition of extra blood spots from negative malaria donors into a reaction did not affect the performance of the single direct COXIII PCR at the lowest $P$. falciparum detected parasitaemia (Fig. 2b).

When the 18s-rRNA nested PCR was validated with the 21 known positive blood samples, the test showed that all samples were positive with the genus malaria PCR (Fig. 2c) and with the species diagnosis as follows: $P$. falciparum $(\mathrm{n}=7), P$. vivax $(\mathrm{n}=5), P$. malariae $(\mathrm{n}=1)$, $P$. ovale $(\mathrm{n}=1)$ and mixed infection $(\mathrm{n}=4)$ (Fig. $2 \mathrm{~d})$, and three samples did not amplify with any of the speciesspecific primers (Table 3). The COX-III single direct PCR amplified the expected band of $500 \mathrm{bp}$, and sequenced all the human Plasmodium parasites used as controls, including all the 21 known positive blood samples (100\% concordance with the 18s-rRNA genus malaria PCR) (Tables 2, 3). When compared with the 18s-rRNA nested PCR, the COX-III sequencing results confirmed species identification results for 14 samples and identified the missed three as $P$. malariae; the predicted four mixed infections were identified as mono-infections by either $P$. vivax or P. falciparum (Table 3).

\section{Mixed infection test using the fast COX-III PCR}

The performance of the COX-III single direct PCR on simulated mixed infections was tested using a range from 0.33 to $1.2 \mathrm{E}-06 \mathrm{ng}$ of DNA from P. falciparum (HB3 strain) and $P$. vivax (Miami strain) (Table 2). For all the different ratios of DNA concentrations in the simulated mixed-infection, the band of about 500 bp was obtained in four independent assays. Sequencing of the COX-III PCR products identified the malaria parasite ( $P$. vivax or 


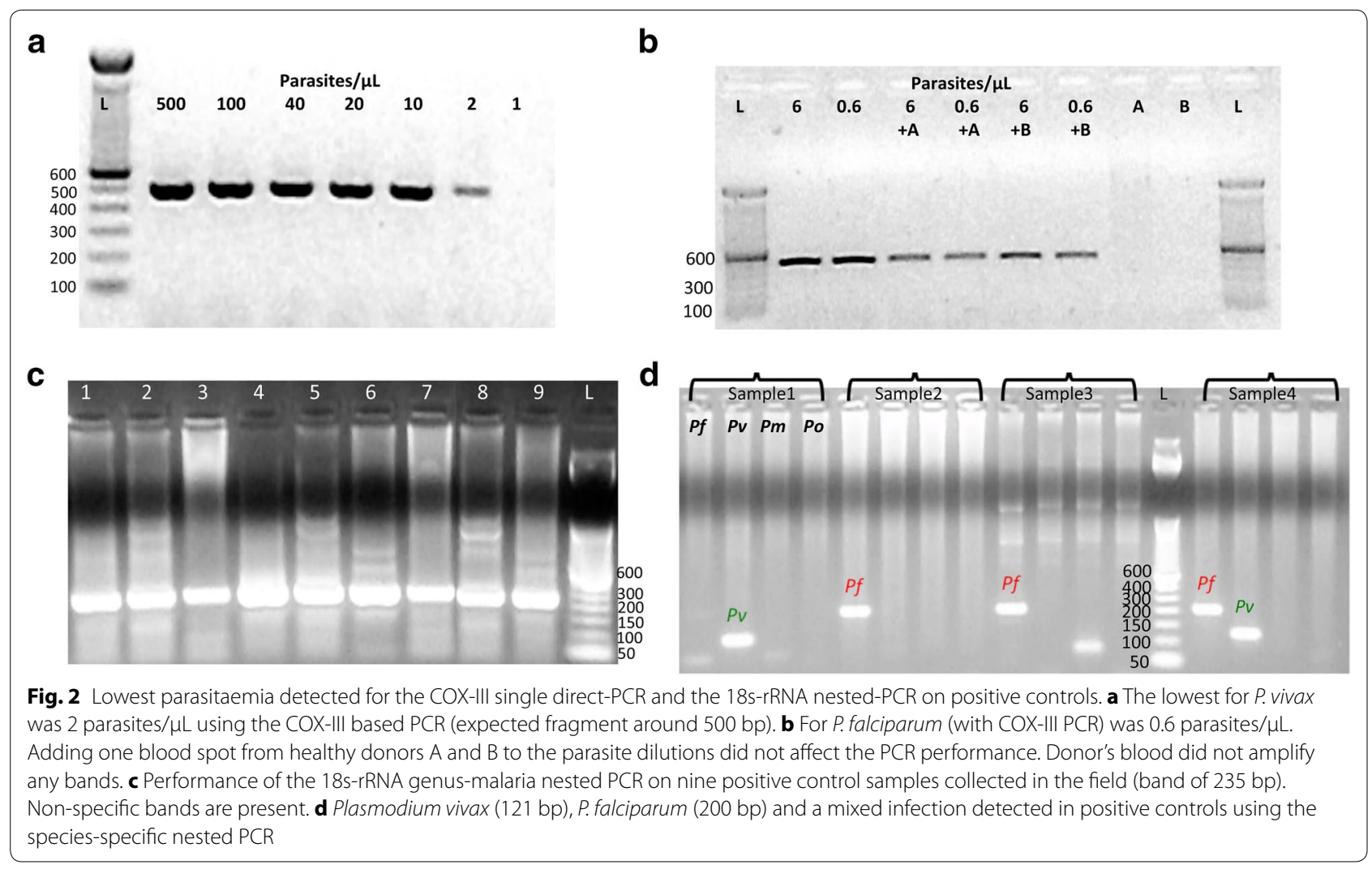

P. falciparum) that had the higher concentration of DNA for a given simulated mixed-infection (Table 2).

\section{Validation of protocols on field samples 18s-rRNA direct nested PCR}

A total of 3833 samples were screened for malaria using the modified 18s-rRNA direct nested PCR (Table 1, Fig. 1). There were 636 (16.6 \%) Plasmodium positive samples with the 235 bp diagnostic band. Faint bands around $235 \mathrm{bp}$ were found singularly or accompanied with strong bands usually above $300 \mathrm{bp}$ without evidence of contamination in the negative control wells. These non-specific amplifications were seen in almost $85 \%$ of all Plasmodium genus PCRs performed (Fig. 3a).

There was a lack of concordance between the genus and species PCRs using the 18s-rRNA direct nested diagnostic assay. All Plasmodium PCR positive samples were only tested for P. falciparum and P. vivax (Fig. 1). About $30 \%$ of the positive genus-Plasmodium samples were positive by species-specific PCR. A total of 179 infections (95.2\%) were diagnosed as $P$. vivax and nine ( $4.8 \%)$ by P. falciparum (overall, $4.9 \%$ of samples were positive). Again, non-specific bands were seen above $300 \mathrm{bp}$ and close to the diagnostic band for P. vivax (Fig. 3b) and $P$. falciparum. The 448/636 samples that did not amplify any of the malaria species, were rerun with the $P$. vivax specific primers (as this is the most prevalent species in the tested samples). For this set of samples amplifications were not obtained.

A total of 100 and 20 predicted positive samples were sequenced to verify Plasmodium spp. and P. vivax diagnosis respectively (Fig. $3 \mathrm{~b}$ ). For the sequencing reactions with Plasmo_int_2REV or rPLU4 primers, only seven samples were identified as $P$. vivax. For the remaining 93 samples, the sequencing results were inconclusive or did not have similarity with any sequence from GenBank. For the 20 sequencing reactions run with VIV1 primer, eight samples showed similarity with $P$. vivax, four were human DNA, and eight had no similarity with any sequence.

\section{COX-III single direct PCR}

The COX-III single direct PCR approach was used for Plasmodium spp. detection in the 3833 samples. The diagnostic band of $500 \mathrm{bp}$ was seen in 79/3833 samples ( $2 \%$ of positive samples) (Fig. 3c). In these samples, a total of 39 and 40 samples were positive from the previously 640 predicted positive and negative samples using the 18s-rRNA direct nested PCR, respectively. When comparing the 3833 set of samples with both PCR approaches (18s-rRNA and COX-III), the COX-III direct PCR detected only $6 \%$ of the 640 predicted positives by the nested PCR. 
Table 3 Comparison of malaria diagnosis on 21 positive samples based on the COX-III single direct-PCR versus the 18s-rRNA nested PCRs

\begin{tabular}{|c|c|c|c|c|}
\hline \multirow[t]{2}{*}{ Sample code } & \multirow[t]{2}{*}{$\begin{array}{l}\text { PCR fragment } \\
\text { of COX-III }\end{array}$} & \multicolumn{2}{|c|}{$\begin{array}{l}\text { PCR fragment } \\
\text { of } 18 \mathrm{~s}-\mathrm{rRNA}\end{array}$} & \multirow[t]{2}{*}{ Agreement } \\
\hline & & Genus & Species & \\
\hline IN01 & P. malariae & + & Negative $^{a}$ & No \\
\hline IN02 & P. falciparum & + & P. falciparum & Yes \\
\hline IN03 & P. falciparum & + & P. falciparum & Yes \\
\hline IN04 & P. falciparum & + & P. falciparum & Yes \\
\hline IN05 & P. vivax & + & P. vivax & Yes \\
\hline IN06 & P. vivax & + & P. vivax & Yes \\
\hline IN07 & P. vivax & + & $\begin{array}{l}\text { Mixed } \\
\text { infection }^{b}\end{array}$ & No \\
\hline IN08 & P. falciparum & + & P. falciparum & Yes \\
\hline IN09 & P. vivax & + & P. vivax & Yes \\
\hline IN10 & P. falciparum & + & P. falciparum & Yes \\
\hline IN11 & P. vivax & + & $\begin{array}{l}\text { Mixed } \\
\text { infection }^{b, c}\end{array}$ & No \\
\hline IN12 & P. vivax & + & $\begin{array}{l}\text { Mixed } \\
\text { infection }^{b}\end{array}$ & No \\
\hline IN13 & P. malariae & + & P. malariae & Yes \\
\hline IN14 & P. falciparum & + & $\begin{array}{l}\text { Mixed } \\
\text { infection }\end{array}$ & No \\
\hline IN15 & P. ovale curtisi & + & P. ovale & Yes \\
\hline IN16 & P. malariae & + & Negative $^{a}$ & No \\
\hline IN17 & P. vivax & + & P. vivax & Yes \\
\hline IN18 & P. vivax & + & P. vivax & Yes \\
\hline IN19 & P. malariae & + & Negative $^{a}$ & No \\
\hline IN20 & P. falciparum & + & P. falciparum & Yes \\
\hline IN21 & P. falciparum & + & P. falciparum & Yes \\
\hline
\end{tabular}

a Negative results was obtain in two independent experiments

b Mixed infections were due to $P$. falciparum and $P$. vivax

c A second technical replicate of this sample was showed as a mono-infection with $P$. vivax

Overall, from the 79 sequenced samples with the short_COX-IIIF primer, $76 \%$ were $P$. vivax, $12 \%$ were P. falciparum, $8 \%$ were $P$. ovale wallikeri and $4 \%$ were P. malariae. A further 3506 blood spots were also tested with this protocol with similar results (data not shown). This method also generated clearer diagnostic bands without non-specific bands (Fig. 3c).

\section{Discussion}

Since 1993, the 18s-rRNA gene has been extensively used in different PCR assays for malaria diagnosis [14, 15, 30, 35-38]. The nested PCR approach has been the most widely used and often regarded as the standard PCR diagnostic method (primarily using high purity DNA and the original protocol), when comparing new PCR-based diagnostic approaches $[17,19,23,39,40]$. The 18s-rRNA nested PCR was not designed to be used with crude blood spots in a direct PCR strategy.

In the present study, the limit of detection or sensitivity, using the 18s-rRNA direct nested PCR was 2 and 10 parasites $/ \mu \mathrm{L}$ for $P$. falciparum and $P$. vivax respectively, which is comparable with previous studies [16-18]. Only 18 of 21 positive control blood spot samples were positives for genus and species, with the three $P$. malariae samples being not detected by the18s-rRNA nested PCR. Whereas, all 21 positive control samples were detected by the COX-III single direct PCR.

Several studies have described inconsistencies in malaria positivity rates when species-specific reactions are performed using the 18s-rRNA gene [14, 19, 41-43] (Table 4). Several problems were identified when using the nested PCR to analyse the field samples: (a) $75 \%$ of positive samples gave discordant diagnoses when genus and species-specific results were compared; (b) it was not possible to confirm predictive positive samples (genus and species PCR) with sequencing; and (c) 40 samples positive with the COX-III single direct PCR were not identified with the18s-rRNA genus nested PCR. Possible explanations for the results from the nested protocol include the following:

1. Amplification of non-specific bands: The amplification of non-specific bands in the nested PCR diagnostic have been described [23, 44] and reported with the primers PLF, UNR and VIR (also targeting the 18s-rRNA gene) [45]. Sequencing of a subset of predicted positive samples for genus and species did not produce readable data $(93 \%$ and $55 \%$ of the samples tested respectively), suggesting non-specific amplification. Without evidence of contamination in the negative controls, the presence of non-specific bands near or at the expected diagnostic band size increased the number of false positives.

2. Lower DNA yield from blood spots: The number of parasites can differ by more than $15 \%$ between different punches from the same bloodspot [22]. It is also suggested that samples analysed from dried blood spots report half the Plasmodium positive rate compared with analyses using whole blood samples [23]. Samples in this study are from a low transmission setting (Western Province, Solomon Islands) under malaria pre-elimination phase, and may have extremely low parasite densities, which may fail to amplify (Monte Carlo effect) [43] or produce inconsistent or unspecific amplifications with a protocol not sensitive enough.

3. The methodology described by Fuehrer et al. [17] utilized phusion blood DNA polymerase, while in this study the phusion blood II DNA polymerase was 


\section{a}

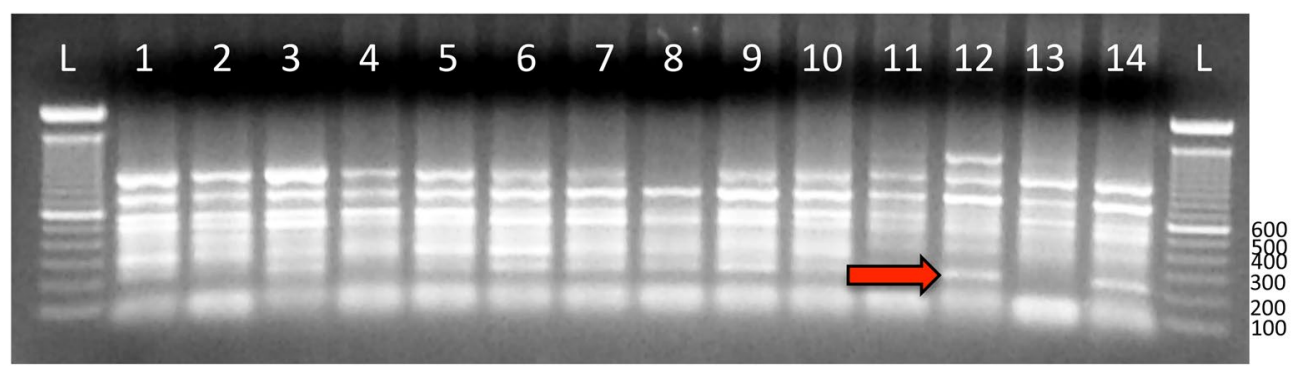

b

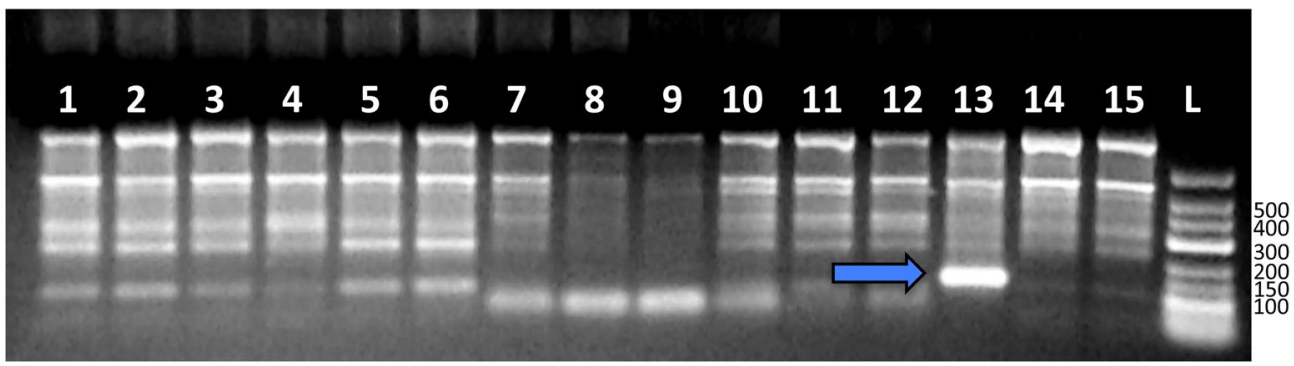

C

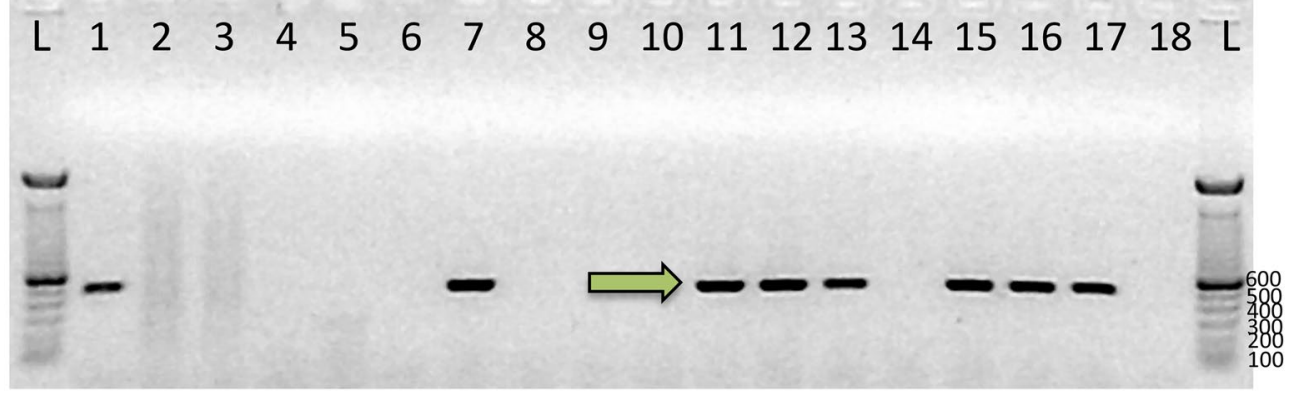

Fig. 3 Performance of the 18s-rRNA nested-PCR and COX-III single direct-PCR on samples from the Solomon Islands. a Strong non-specific bands in 14 samples were amplified when the genus-malaria 18s-rRNA nested PCR was used. The expected diagnostic band for Plasmodium spp is $235 \mathrm{bp}$ (red arrow). b Nonspecific bands close to the 121 bp diagnostic bands for P. vivax (blue arrow); only the sample 13 shown a robust band. c Eighteen samples tested for Plasmodium spp using the COX-III gene, a band of approximately 500 bp (green arrow) represent positive samples

Table 4 Summary of inconclusive results when the 18s-rRNA species-specific primers are used for malaria diagnosis

\begin{tabular}{llll}
\hline Location & $\begin{array}{l}\text { Proportion of inconsistent } \\
\text { species-specific } \\
\text { identification over total } \\
\text { predicted positives for genus (\%) }\end{array}$ & Source material (DNA extraction method) & \\
\hline Cambodia & $12 / 256(4.7)^{\mathrm{a}}$ & Blood spots (commercial kit and instagene) & {$[19]$} \\
Tanzania & $21 / 76(27.6)^{\mathrm{b}}$ & Whole blood (commercial kit) & {$[41]$} \\
Brazil & $13 / 34(38)^{\mathrm{c}}$ & Whole blood (commercial kit) & {$[43]$} \\
Malaysia & $3 / 46(6.5)^{\mathrm{a}}$ & Blood spots (chelex) & {$[14]$} \\
Bangladesh & $2 / 97(2)^{\mathrm{a}}$ & Blood spots (direct PCR) and (instagene-chelex) \\
Nigeria & $37 / 285(13)^{\mathrm{d}}$ & Blood spots (commercial kit) & {$[21]$} \\
\hline
\end{tabular}

a 18 s-rRNA genus were positive but no species identified by nested PCR

b The genus diagnostic was based on mitochondrial DNA while specie-specific diagnosis targeted the 18s rRNA

c 13 samples were tested by quadruplicate with species-specific primers without reproducible results

d Results from P. falciparum specific primers (rFAL1/rFAL2) were compared against composite reference results 
used. The phusion blood II DNA polymerase in the direct PCR kit contains an improved affibody molecule which allows for lower annealing temperatures and wider range of PCR primers, this may explain the non-specific bands seen here, and may require extra optimization of temperatures with a gradient cycler. This issue was not seen when the phusion blood DNA polymerase was used.

4. Presence of blood inhibitors: Blood has potent PCR inhibitors such as haemoglobin, hemin, immunoglobulin $\mathrm{G}$ and lactoferrin $[46,47]$. In PCR reactions, the Taq polymerase enzyme is completely inhibited in the presence of $0.004 \%(\mathrm{v} / \mathrm{v})$ of human blood [48]. Blood compounds transferred from the first PCR product (nest1) to the second (nest2) PCR reaction might affect amplification of target DNA.

The lowest parasitaemia detected with the COX-III single direct PCR ( $\leq 2$ parasites/ul found in P. vivax and $P$. falciparum) is comparable with malaria diagnostic techniques based on mitochondrial or Pfr364 and Pvr47 genes, LAMP isothermal reactions, real time PCR and single PCRs [23, 39, 49, 50]; and better when compared with 18s-rRNA isothermal reactions, real time and multiplex PCRs [37, 51, 52]. Differences in sensitivity are correlated with: (1) higher copy numbers of COX-III and other mitochondrial genes (up to 150) in comparison with up to 8 copies in the 18s-rRNA gene [40], (2) stringent design of primers (100 and $66 \%$ similarity with Plasmodium and human DNA respectively) and (3) the robustness and accuracy of the phusion blood II DNA polymerase used in the direct PCR. In a recent manuscript, a new efficient PCR (one round) based on the COX-III gene (using purified DNA) for Plasmodium genus detection was described, with nested PCRs required for Plasmodium species identification [40].

The use of direct PCR avoids DNA extraction/purification steps, thereby retaining all DNA in the sample while reducing the risk of cross-contamination. The practicality and shorter time-to-result with the single COX-III direct PCR $(1 \mathrm{~h})$ compared with other PCR assays make this technique suitable for large-scale application and highthroughput analyses, while also dramatically reducing time, effort and resources. The single COX-III direct PCR is also less expensive. The cost of malaria diagnosis of 96 blood spots with 10 positive samples (for species identification) using the single direct COX-III PCR (including only the single COX-III PCRs, PCR product purification and sequencing) can be up to a quarter of the cost when compared with the 18s-rRNA nested PCR (192 PCRs for genus diagnosis and 50 for species diagnosis) as described here, the COX-III PCR assay developed by
Isozumi et al. [40], and a 18s-rRNA real time PCR strategy [39].

Only a few protocols have been designed to discriminate between the species $P$. ovale curtisi (classic type) and P. ovale wallikeri (variant type) $[18,53]$. There are 97 predicted polymorphisms (88 SNPs and 9 INDELs) between the P. ovale wallikeri (HQ712053.1) and P. ovale curtisi (HQ712052.1) mitochondrial genomes (5850 bp). The COX-III single direct PCR amplifies a 506 bp fragment, which has 16 SNPs (16.5\% of the total polymorphisms) accounting for an accurate diagnosis for both species. A positive control sample from the field was identified as $P$. ovale curtisi while $P$. ovale wallikeri was found in a reference control and three samples from the larger dataset (Tables 2, 3).

Mixed Plasmodium infection diagnosis is rare (up to $4 \%$ ) with microscopy but common (up to $65 \%$ ) when PCR techniques are used [54]. The single COX-III direct PCR was able to detect only one species in the three predicted mixed infections detected by the nested 18s-rRNA in positive control samples (Table 3). Also, the new technique consistently amplified parasite DNA in mock mixed infections ( $P$. vivax and $P$. falciparum), but the sequencing reactions only detected the predominant infection (Table 2). This is consistent with previous studies when the difference of DNA concentration is $>10$-fold between parasites in a mixed infection, only the most abundant parasite is amplified when multiplex PCR or real time techniques are used [51]. The use of specific primers for each Plasmodium species may be the most precise approach for determining species in mixed malaria infections.

\section{Conclusions}

In conclusion, a cheaper, faster, and more sensitive PCR/ sequencing method to accurately identify all human malaria parasites (including the $P$. ovale sub-species) was developed and tested on more than 7000 blood spots, using the cytochrome oxidase III (COX-III) as target. This method will simplify screening samples as well as minimize chances of contamination as DNA extraction and nested PCR reactions are not required. This sensitive diagnostic tool will be useful in detecting submicroscopic and/or asymptomatic malaria when active screening a large number of subjects.

\footnotetext{
Abbreviations

18s-rRNA: 18 small subunit ribosomal RNA; ACT: artemisinine combinatory therapy; COX-III: cytochrome oxidase III; IRS: indoor residual spraying; ITNs: insecticide-treated bednets; mm: millimeter; MR4: malaria Research and Reference Reagent Resource Center; MSA-2: merozoite surface antigen 2; ng: nanograms; RDT: rapid diagnostic test; Sec: seconds; STEVOR: subtelomeric variable open reading frame; $\mu \mathrm{L}$ : microlitre.
} 


\section{Authors' contributions}

DFE: Conceived and designed the COX-III direct PCRs, performed laboratory work (molecular diagnostic PCRs and sequencing experiments), data analyses and writing of the manuscript. NAD, JD, VM, HX, JN and MK: Participated in laboratory work, data analyses and critically reviewed the manuscript. TLR and TRB: Participated in blood spot sample collection and critically reviewed the manuscript. FHC: Participates in supervision of the study and critically review the manuscript. NFL: Participated in the blood spot sample collection and in laboratory work, supervision of the study, data analyses and critically reviewed the manuscript. All authors read and approved the final manuscript.

\section{Author details}

${ }^{1}$ Eck Institute for Global Health, University of Notre Dame, Notre Dame, IN 46556, USA. ${ }^{2}$ Australian Institute of Tropical Health and Medicine, James Cook University, Cairns, QLD 4870, Australia.

\section{Acknowledgements}

This project has been funded in whole or in part with funds from the Bill and Melinda Gates Foundations under Grant No. 45114. The authors would like to thank The Solomon Island Ministry of Health, study participants and communities in Western Province, Solomon Islands, and healthcare professionals for their assistance in sample procurement, particularly Hendrick Reuben and Jance Oscar. Thanks to Ngor Majak Anyieth, Heather Boldt, Brooke Brown, Daniel Olivieri, Daniel Pichler, Keith Loh, Emily Kruse, Xiaoyu Yu and Thomas Rieth for their invaluable help in the lab.

\section{Competing interests}

The authors declare that they have no competing interests.

Received: 7 October 2015 Accepted: 20 February 2016

Published online: 29 February 2016

\section{References}

1. Alonso PL, Brown G, Arevalo-Herrera M, Binka F, Chitnis C, Collins F, et al. A research agenda to underpin malaria eradication. PLos Med. 2011;8:e1000406.

2. WHO. World malaria report 2014. Geneva: World Health Organization; 2014

3. Alonso P, Barnwell J, Bell D, Hanson K, Mendis K, Moonen B, et al. A research agenda for malaria eradication: diagnoses and diagnostics. PLos Med. 2011;8:e1000396.

4. Lindblade KA, Steinhardt L, Samuels A, Kachur SP, Slutsker L. The silent threat: asymptomatic parasitemia and malaria transmission. Expert Rev Anti Infect Ther. 2013;11:623-39.

5. Wongsrichanalai C, Barcus MJ, Muth S, Sutamihardja A, Wernsdorfer WH. A review of malaria diagnostic tools: microscopy and rapid diagnostic test (RDT). Am J Trop Med Hyg. 2007;77:119-27.

6. Moody A. Rapid diagnostic tests for malaria parasites. Clin Microbiol Rev. 2002;15:66-78

7. Pava Z, Echeverry DF, Díaz G, Murillo C. Large variation in detection of histidine-rich protein 2 in Plasmodium falciparum isolates from Colombia. Am J Trop Med Hyg. 2010;83:834-7.

8. Bell DR, Wilson DW, Martin LB. False-positive results of a Plasmodium falciparum histidine-rich protein 2-detecting malaria rapid diagnostic test due to high sensitivity in a community with fluctuating low parasite density. Am J Trop Med Hyg. 2005;73:199-203.

9. Chiodini PL, Bowers K, Jorgensen P, Barnwell JW, Grady KK, Luchavez J, et al. The heat stability of Plasmodium lactate dehydrogenase-based and histidine-rich protein 2-based malaria rapid diagnostic tests. Trans R Soc Trop Med Hyg. 2007;101:331-7.

10. Rennie W, Phetsouvanh R, Lupisan S, Vanisaveth V, Hongvanthong B, Phompida $S$, et al. Minimising human error in malaria rapid diagnosis: clarity of written instructions and health worker performance. Trans R Soc Trop Med Hyg. 2007;101:9-18.

11. WHO. Malaria Rapid Diagnostic Test Performance. Summary results of WHO product testing of malaria RDTs: Round 1-5 (2008-2013). Geneva: World Health Organization; 2014.
12. Cheng Q, Cunningham J, Gatton ML. Systematic Review of Sub-microscopic P. vivax infections: prevalence and determining factors. PLos Neg Trop Dis. 2015;9:e3413.

13. Okell LC, Ghani AC, Lyons E, Drakeley CJ. Submicroscopic infection in Plasmodium falciparum-endemic populations: a systematic review and meta-analysis. J Infect Dis. 2009;200:1509-17.

14. Singh B, Bobogare A, Cox-Singh J, Snounou G, Abdullah MS, Rahman HA. A genus- and species-specific nested polymerase chain reaction malaria detection assay for epidemiologic studies. Am J Trop Med Hyg. 1999;60:687-92.

15. Snounou G, Pinheiro L, Gonçalves A, Fonseca L, Dias F, Brown KN, et al. The importance of sensitive detection of malaria parasites in the human and insect hosts in epidemiological studies, as shown by the analysis of field samples from Guinea Bissau. Trans R Soc Trop Med Hyg. 1993;87:649-53.

16. Snounou G, Singh B. Nested PCR analysis of Plasmodium parasites. Methods Mol Med. 2002;72:189-203.

17. Fuehrer HP, Fally MA, Habler VE, Starzengruber P, Swoboda P, Noedl H. Novel nested direct PCR technique for malaria diagnosis using filter paper samples. J Clin Microbiol. 2011;49:1628-30.

18. Fuehrer HP, Noedl H. Recent advances in detection of Plasmodium ovale: implications of separation into the two species Plasmodium ovale walliker and Plasmodium ovale curtisi. J Clin Microbiol. 2014;52:387-91.

19. Steenkeste N, Incardona S, Chy S, Duval L, Ekala MT, Lim P, et al. Towards high-throughput molecular detection of Plasmodium: new approaches and molecular markers. Malar J. 2009;8:86.

20. Steenkeste N, Rogers WO, Okell L, Jeanne I, Incardona S, Duval L, et al. Sub-microscopic malaria cases and mixed malaria infection in a remote area of high malaria endemicity in Rattanakiri province, Cambodia: implication for malaria elimination. Malar J. 2010;9:108.

21. Oyedeji SI, Awobode HO, Monday GC, Kendjo E, Kremsner PG, Kun JF. Comparison of PCR-based detection of Plasmodium falciparum infections based on single and multicopy genes. Malar J. 2007;6:112.

22. Polley SD, Mori Y, Watson J, Perkins MD, Gonzalez IJ, Notomi T, et al. Mitochondrial DNA targets increase sensitivity of malaria detection using loop-mediated isothermal amplification. J Clin Microbiol. 2010;48:2866-71.

23. Demas A, Oberstaller J, DeBarry J, Lucchi NW, Srinivasamoorthy G, Sumari $D$, et al. Applied genomics: data mining reveals species-specific malaria diagnostic targets more sensitive than 185 rRNA. J Clin Microbiol. 2011:49:2411-8.

24. Fontecha GA, Mendoza M, Banegas E, Poorak M, De Oliveira AM, Mancero T, et al. Comparison of molecular tests for the diagnosis of malaria in Honduras. Malar J. 2012;11:119.

25. Kermekchiev MB, Kirilova LI, Vail EE, Barnes WM. Mutants of Taq DNA polymerase resistant to PCR inhibitors allow DNA amplification from whole blood and crude soil samples. Nucleic Acids Res. 2009;37:e40.

26. Silbermayr K, Eigner B, Duscher GG, Joachim A, Fuehrer HP. The detection of different Dirofilaria species using direct PCR technique. Parasitol Res. 2014;113:513-6.

27. Reptova S, Trtkova KS, Kolar Z. Direct detection of the AR-E211 G > A gene polymorphism from blood and tissue samples without DNA isolation. Pathol Oncol Res. 2014;20:223-7.

28. Cascella R, Strafella C, Ragazzo M, Zampatti S, Borgiani P, Gambardella S, et al. Direct PCR: a new pharmacogenetic approach for the inexpensive testing of HLA-B*57:01. Pharmacogenomics J. 2015;15:196-200.

29. Aboud M, Oh HH, McCord B. Rapid direct PCR for forensic genotyping in under 25 min. Electrophoresis. 2013;34:1539-47.

30. Taylor BJ, Martin KA, Arango E, Agudelo OM, Maestre A, Yanow SK. Realtime PCR detection of Plasmodium directly from whole blood and filter paper samples. Malar J. 2011;10:244.

31. McMorrow ML, Aidoo M, Kachur SP. Malaria rapid diagnostic tests in elimination settings-can they find the last parasite? Clin Microbiol Infect. 2011;17:1624-31.

32. Xu W, Morris U, Aydin-Schmidt B, Msellem MI, Shakely D, Petzold M, et al. SYBR Green real-time PCR-RFLP assay targeting the Plasmodium cytochrome B gene-a highly sensitive molecular tool for malaria parasite detection and species determination. PLoS ONE. 2015;10:e0120210.

33. Corpet $F$. Multiple sequence alignment with hierarchical clustering. Nucleic Acids Res. 1988;16:10881-90 
34. Thermo-Fisher Scientific. User Guide: Phusion Blood Direct PCR Kit. Waltham; 2015.

35. Snounou G, Viriyakosol S, Jarra W, Thaithong S, Brown KN. Identification of the four human malaria parasite species in field samples by the polymerase chain reaction and detection of a high prevalence of mixed infections. Mol Biochem Parasitol. 1993;58:283-92.

36. Padley D, Moody AH, Chiodini PL, Saldanha J. Use of a rapid, single-round, multiplex PCR to detect malarial parasites and identify the species present. Ann Trop Med Parasitol. 2003;97:131-7.

37. Kersting S, Rausch V, Bier FF, von Nickisch-Rosenegk M. Rapid detection of Plasmodium falciparum with isothermal recombinase polymerase amplification and lateral flow analysis. Malar J. 2014;13:99.

38. Rubio JM, Benito A, Roche J, Berzosa PJ, Garcia ML, Mico M, et al. Seminested, multiplex polymerase chain reaction for detection of human malaria parasites and evidence of Plasmodium vivax infection in Equatorial Guinea. Am J Trop Med Hyg. 1999;60:183-7.

39. Canier L, Khim N, Kim S, Sluydts V, Heng S, Dourng D, et al. An innovative tool for moving malaria PCR detection of parasite reservoir into the field. Malar J. 2013;12:405

40. Isozumi R, Fukui M, Kaneko A, Chan CW, Kawamoto F, Kimura M. Improved detection of malaria cases in island settings of Vanuatu and Kenya by PCR that targets the Plasmodium mitochondrial cytochrome $c$ oxidase III (cox3) gene. Parasitol Int. 2015;64:304-8.

41. Strom GE, Haanshuus CG, Fataki M, Langeland N, Blomberg B. Challenges in diagnosing paediatric malaria in Dar es Salaam, Tanzania. Malar J. 2013;12:228.

42. Haanshuus CG, Mohn SC, Morch K, Langeland N, Blomberg B, Hanevik K. A novel, single-amplification PCR targeting mitochondrial genome highly sensitive and specific in diagnosing malaria among returned travellers in Bergen, Norway. Malar J. 2013;12:26.

43. Costa DC, Madureira AP, Amaral LC, Sanchez BA, Gomes LT, Fontes CJ, et al. Submicroscopic malaria parasite carriage: how reproducible are polymerase chain reaction-based methods? Mem Inst Oswaldo Cruz. 2014;109:21-8.

44. Bass C, Nikou D, Blagborough AM, Vontas J, Sinden RE, Williamson MS, et al. PCR-based detection of Plasmodium in Anopheles mosquitoes: a comparison of a new high-throughput assay with existing methods. Malar J. 2008;7:177.

45. Harrison GF, Foley DH, Rueda LM, Melanson VR, Wilkerson RC, Long LS, et al. Plasmodium-specific molecular assays produce uninterpretable results and non-Plasmodium spp. sequences in field-collected Anopheles vectors. Am J Trop Med Hyg. 2013;89:1117-21.

46. Radstrom P, Knutsson R, Wolffs P, Lovenklev M, Lofstrom C. Pre-PCR processing - Strategies to generate PCR-compatible samples. Mol Biotechnol. 2004;26:133-46.

47. Wilson IG. Inhibition and facilitation of nucleic acid amplification. Appl Environ Microb. 1997;63:3741-51.

48. Abu Al-Soud W, Radstrom P. Capacity of nine thermostable DNA polymerases to mediate DNA amplification in the presence of PCR-inhibiting samples. Appl Environ Microb. 1998;64:3748-53.

49. Aydin-Schmidt B, Xu W, Gonzalez IJ, Polley SD, Bell D, Shakely D, et al. Loop mediated isothermal amplification (LAMP) accurately detects malaria DNA from filter paper blood samples of low density parasitaemias. PLOS ONE. 2014;9:e103905.

50. Farrugia C, Cabaret O, Botterel F, Bories C, Foulet F, Costa JM, et al. Cytochrome b gene quantitative PCR for diagnosing Plasmodium falciparum infection in travelers. J Clin Microbiol. 2011;49:2191-5.

51. Mixson-Hayden T, Lucchi NW, Udhayakumar V. Evaluation of three PCRbased diagnostic assays for detecting mixed Plasmodium infection. BMC Res Notes. 2010;3:88.

52. Veron V, Simon S, Carme B. Multiplex real-time PCR detection of $P$. falciparum, P. vivax and P. malariae in human blood samples. Exp Parasitol. 2009; $121: 34651$.

53. Sutherland CJ, Tanomsing N, Nolder D, Oguike M, Jennison C, Pukrittayakamee $\mathrm{S}$, et al. Two nonrecombining sympatric forms of the human malaria parasite Plasmodium ovale occur globally. J Infect Dis. 2010;201:1544-50.

54. Mayxay M, Pukrittayakamee S, Newton PN, White NJ. Mixed-species malaria infections in humans. Trends Parasitol. 2004;20:233-40.

\section{Submit your next manuscript to BioMed Central and we will help you at every step:}

- We accept pre-submission inquiries

- Our selector tool helps you to find the most relevant journal

- We provide round the clock customer support

- Convenient online submission

- Thorough peer review

- Inclusion in PubMed and all major indexing services

- Maximum visibility for your research

Submit your manuscript at www.biomedcentral.com/submit

\section{() Biomed Central}

